$\begin{array}{cc}\text { ACADEMIA ROMÂNĂ } & \text { Rev. Roum. Chim., } \\ \text { 2020, 65(4), 343-352 }\end{array}$

\title{
SYNTHESIZE PALLADIUM AND NICKEL OXIDE NANOPARTICLES IN THE PRESENCE OF 4-AMINOANTIPYRINE DERIVATIVE AS A PRECURSOR: DECOLORIZATION EFFICIENCY OF METHYLENE BLUE
}

\author{
Khuloud A. ALIBRAHIM, ${ }^{\mathrm{a}, *}$ Foziah F. AL-FAWZAN ${ }^{\mathrm{a}}$ and Moamen S. REFAT ${ }^{\mathrm{b}, \mathrm{c}, *}$ \\ ${ }^{\mathrm{a} C}$ College of Science, Princess Nourah bint Abdulrahman University, Department of Chemistry, KSA \\ ${ }^{b}$ Department of Chemistry, Faculty of Science, Taif University, Al-Hawiah, Taif, P.O. Box 888 Zip Code 21974, Saudi Arabia \\ ${ }^{c}$ Department of Chemistry, Faculty of Science, Port Said University, Port Said, Egypt
}

Received September 9, 2019

This paper discussed the preparation of palladium (PdO) and nickel (NiO) oxides nanoparticles (NPs). These nanoparticle oxides were successfully synthesized by thermal decomposition method using complexes of Schiff base of 4-aminoantipyrine derivative as a precursor at temperature of $800{ }^{\circ} \mathrm{C}$. Schiff base (AEB) was synthesized via a reaction between 4-aminoantipyrine, benzaldehyde and ethylenediamine at stoichiometric 1:1:1 molar ratio at $60{ }^{\circ} \mathrm{C}$ for $2 \mathrm{~h}$. The suggested structure of Schiff base was predicted by elemental analyses, ${ }^{1} \mathrm{H}$ - and ${ }^{13} \mathrm{C}-\mathrm{NMR}$, FT-IR, UV-Vis, mass, and thermogravimetric (TGA) techniques. The prepared oxides were characterized by Fourier transform infrared spectrometry (FT-IR), powder X-ray diffraction (XRD), and transmission electron microscopy (TEM). From XRD data, the final thermal decomposition products are PdO and NiO with the particle size of 28 and $13 \mathrm{~nm}$, respectively. From the TEM micrographs, the particle size are in good agreement with XRD data and indicate that the products have uniformly spherical particles. The synthesized $\mathrm{PdO}$ and $\mathrm{NiO}$ oxide nanoparticles were used to removal of the methylene blue (MB) from aqueous solution. Adsorption of MB dye onto the synthesized oxide NPs were performed based on various parameters such as effect of adsorbent dosage, contact time and $\mathrm{pH}$ of the pollutant media. The results suggest that the PdO and NiO NPs are excellent adsorbent for the removal of MB dye.

\section{INTRODUCTION}

The discharge of high-color liquid waste into natural water bodies is not only aesthetically beautiful, but it also impairs the penetration of light, thus disturbing biological processes within a watercourse $^{1,2}$ In addition, many dyes are toxic to some living organisms causing direct destruction of aquatic communities. Some dyes can cause allergic dermatitis, skin irritation, cancer and mutation in humans. Among the various varieties, the basic dyes and azo dyes were found to be the smartest chapters used in the textile industry, since the value of these materials is high. ${ }^{3,4}$

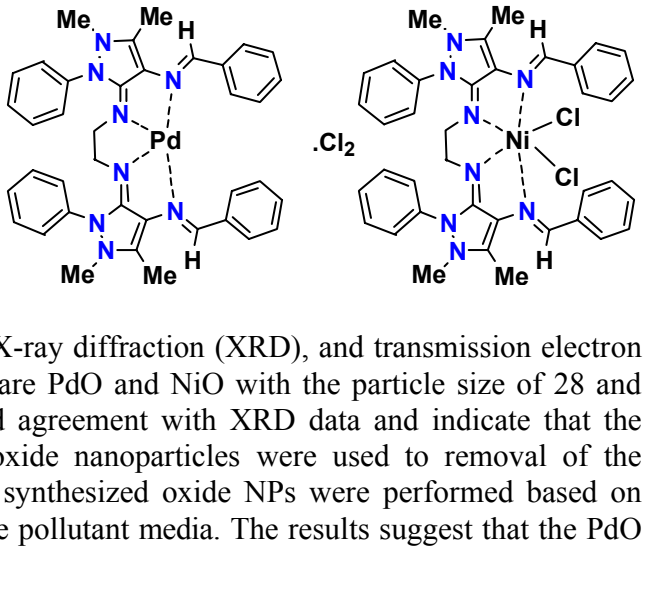

Methylene blue (MB) is a cationic thiazide dye that is commonly used for coloring. It is generally used for dyeing cotton, wool and silk. MB can cause human eye burns, methemoglobinemia, cyanosis, convulsions, tachycardia, dyspnea, irritation to the skin, and if ingested, irritation to the gastrointestinal tract, nausea, vomiting, and diarrhea. ${ }^{5}$ Therefore, decolonization of dyes is an important aspect of wastewater treatment before discharge. It is difficult to remove dyes from effluents, because dyes cannot be readily decomposed and are not generally removed from wastewater by traditional wastewater networks. Therefore, color removal was extensively studied

\footnotetext{
*Corresponding author: msrefat@yahoo.com
} 
with physicochemical methods such as coagulation and flotation, ${ }^{6}$ ozonization, ${ }^{7}$ membrane separation ${ }^{8}$ and adsorption ${ }^{9}$ extensively employed due to its efficiency and economy. ${ }^{10,11}$ Significant researches have been carried out on the absorption of dyes by sorbents such as activated carbon, silica, clay, natural and synthetic polymers, etc. ${ }^{12-16}$ Metalbased NPs have attracted considerable scientific interest in nanotechnology, that noble metals have distinct catalytic, electronic, magnetic, optical and mechanical properties. ${ }^{17}$

The nickel oxide is one of the good adsorbent because of its chemical and magnetic properties. ${ }^{18}$ $\mathrm{NiO}$ oxide solid powder with nanoparticle sizes were used in many industrial applications such as ceramic, producing films, alkaline batteries, magnetic materials, heterogeneous catalytic materials, electrochrom, etc. ${ }^{19-21}$ Nickel oxide as an effective catalyst has been used for oxidation of a wide range of organic compounds. ${ }^{22}$

The study of the potential properties and uses of noble NPs has emerged as very important and valuable to the potential benefits of a number of various applications. In this regard, palladium is a rare precious metal belonging to the platinum group. It is largely used as an active catalyst in catalytic converters, but it also finds application in the electronic, engineering, biomedical and jewelry sectors. ${ }^{17,23}$ Palladium-NPs provide the opportunity to be more effective catalysts due to their high surface area to volume ratio and high surface energy. ${ }^{24}$ Palladium-NPs have priceless, mechanical and optical properties that may provide an opportunity to be used in a number of industrial applications. In this regard, Pd-NPs have been extensively tested for a wide range of chemical applications. ${ }^{25}$

The aim and the novelty of this article are summarized in the following items: (i) Using a simple and low cost organic materials, synthesis of $\mathrm{PdO}$ and NiO NPs oxides dependent on thermal decompositions of AEB Schiff base complexes at $800{ }^{\circ} \mathrm{C}$, (ii) study the possibility of $\mathrm{PdO}$ and $\mathrm{NiO}$ oxides NPs to removal of methylene blue dye, and (iii) define the effects of different factors such as contact time, $\mathrm{pH}$ and adsorbent dosage on the removal efficiency of MB onto PdO and NiO NPs.

\section{EXPERIMENTAL}

\section{Chemicals}

These mentioned pure grade (99\%-99.5\%) chemicals were received from Aldrich-Sigma chemical company and used without further purification: 4-aminoantipyrine, ethylenediamine, benzaldehyde, palladium(II) chloride, nickel(II) chloride, dimethyl sulfoxide, methanol, methylene blue.

\section{Synthesis of AEB Schiff base ligand}

The synthesis of pale yellow AEB Schiff base ligand (Fig. 1), which derives from the condensation reaction of $2 \mathrm{mmol}$ of benzaldehyde with $2 \mathrm{mmol}$ of 4-aminoantipyrine and $1 \mathrm{mmol}$ of ethylenediamine in methanol at $60{ }^{\circ} \mathrm{C}$ for $2 \mathrm{~h}$ has been previously reported. ${ }^{26}$ Yield $=63 \%$ and $\mathrm{mp}=209^{\circ} \mathrm{C}$.

${ }^{1} \mathrm{H}$ NMR (400 MHz, DMSO- $\left.d_{6}\right): \delta=2.18(s, 6 \mathrm{H}$, $\left.2 \mathrm{CH}_{3(\mathrm{C} 3)}\right) ; 2.69\left(\mathrm{~s}, 4 \mathrm{H}, 2 \mathrm{CH}_{2}\right) ; 3.11\left(\mathrm{~s}, 6 \mathrm{H}, 2 \mathrm{NCH}_{3}\right) ; 7.35-7.83$ $\left(\mathrm{m}, 20 \mathrm{H}\right.$, phenyl) and ${ }^{13} \mathrm{C}$ NMR $\left(100 \mathrm{MHz}, \mathrm{DMSO}-d_{6}\right): \delta=$ $12.59,34.83\left(2 \mathrm{CH}_{3}\right), 52.16\left(\mathrm{CH}_{2}\right), 122.7,123.3,126.8,127.2$, $130.3,132.2,133.6,133.8,135.9,146.4,158 ., 162.5(\mathrm{~N}-\mathrm{C}$, $\mathrm{C}=\mathrm{C}, \mathrm{C}=\mathrm{N}$ ). Mass spectrum, $\mathrm{m} / \mathrm{z}$ (int. \%, Scheme 1): 606 (14.4) $\mathrm{M}^{+}, 591$ (12.3), 503 (10.5), 318 (43.9), 290 (35.7), 289 (25.4, 213 (24.5), 198 (22.7), 187 (48.9), 186 (28.8), 172 (30.2), 105 (15.3), 104 (11.2), 95 (54.4), 77 (100). Elemental analysis: Calc. (\%): C, 75.22; H, 6.31; N, 18.47. Found (\%): C, 75.09; H, 6.22; N, 18.41 .

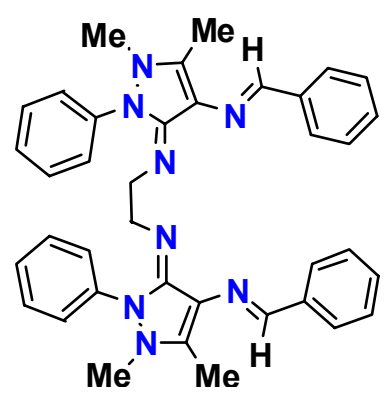

Fig. 1 - Chemical structure of AEB Schiff base ligand.

\section{Synthesis of Pd(II) and Ni(II) Schiff base complexes as a precursors}

General procedure: $2 \mathrm{mmol}$ of AEB Schiff base ligand was mixed with $2 \mathrm{mmol}$ of $\mathrm{PdCl}_{2}$ and $\mathrm{NiCl}_{2}$ in $50 \mathrm{~mL}$ of ethanol solvent. The reaction mixtures were refluxed for $3 \mathrm{~h}$ at $\sim 70{ }^{\circ} \mathrm{C}$. The solutions were filtered off and left to slowly evaporated, after $24 \mathrm{~h}$, the colored microcrystalline precipitates were deposited, collected with filtration, washed with ethanol and few drops of diethyl ether then dried under vacuum. $[\mathrm{Pd}(\mathrm{AEB})] \mathrm{Cl}_{2}$ complex (I): MWt: $784.09 \mathrm{~g} / \mathrm{mol}$; Yield: 76\%; brown color; electrolyte $\left(94 \Omega^{-1} \mathrm{~cm}^{2} \mathrm{~mol}^{-1}\right)$; Anal. Calcd.: C, 58.21; H, 4.88; N, 14.29; Cl, 9.04; Pd, 13.57 . Found: C, 58.06; H, 4.79; N, 14.18; Cl, 8.95; Pd, 13.41\%. [Ni(AEB) $(\mathrm{Cl})_{2}$ ] complex (II): MWt: $736.36 \mathrm{~g} / \mathrm{mol}$; Yield: $78 \%$; greenish brown color; non-electrolyte $\left(19 \Omega^{-1} \mathrm{~cm}^{2} \mathrm{~mol}^{-1}\right)$; Anal. Calcd.: C, 61.98; H, 5.20; N, 15.22; Cl, 9.63; Ni, 7.97. Found: C, 61.88; H, 5.12; N, 15.05; Cl, 9.54; Ni, 7.91\%. Figure 2 referred to structure of complexes.

\section{Synthesis of PdO and NiO NPs}

The resulting AEB Schiff base complexes were thermally decomposed by heating at $800{ }^{\circ} \mathrm{C}$ for $3 \mathrm{~h}$. Both palladium(II) and nickel(II) Schiff complexes decomposed into metal oxide on heating as follows:

$$
\begin{gathered}
{[\mathrm{Pd}(\mathrm{AEB})] \mathrm{Cl}_{2} \rightarrow \mathrm{PdO}+\mathrm{AEB}+\mathrm{Cl}_{2}} \\
{\left[\mathrm{Ni}(\mathrm{AEB})(\mathrm{Cl})_{2}\right] \rightarrow \mathrm{NiO}+\mathrm{AEB}+\mathrm{Cl}_{2}}
\end{gathered}
$$

Infrared spectra, transmission electron microscope (TEM), and X-ray a diffractometer (XRD) were used to characterize the metal oxide adsorbent for its morphological information. 

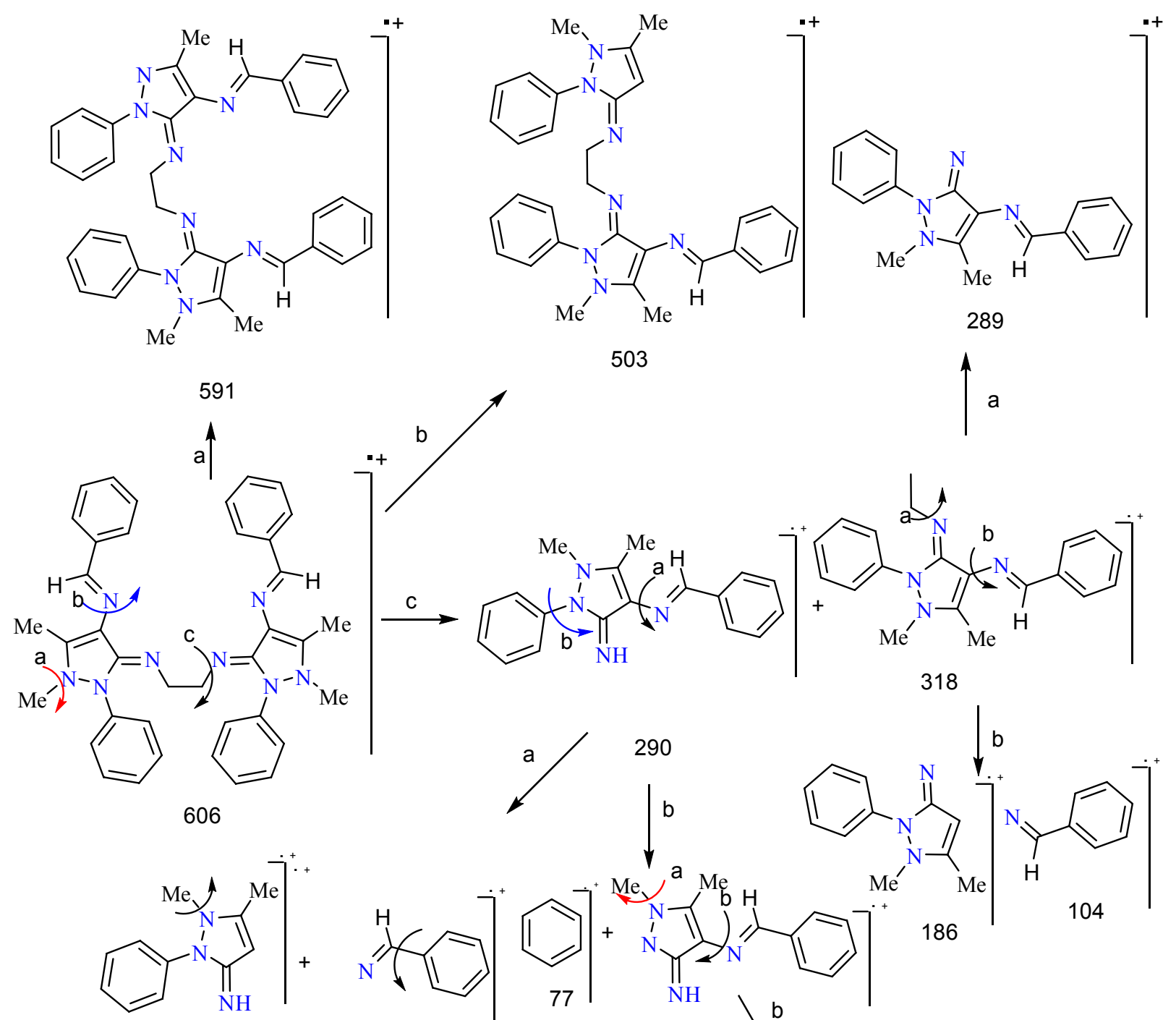

187

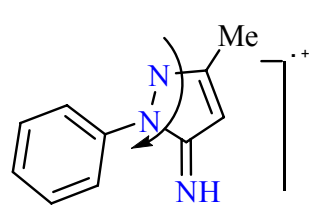

104
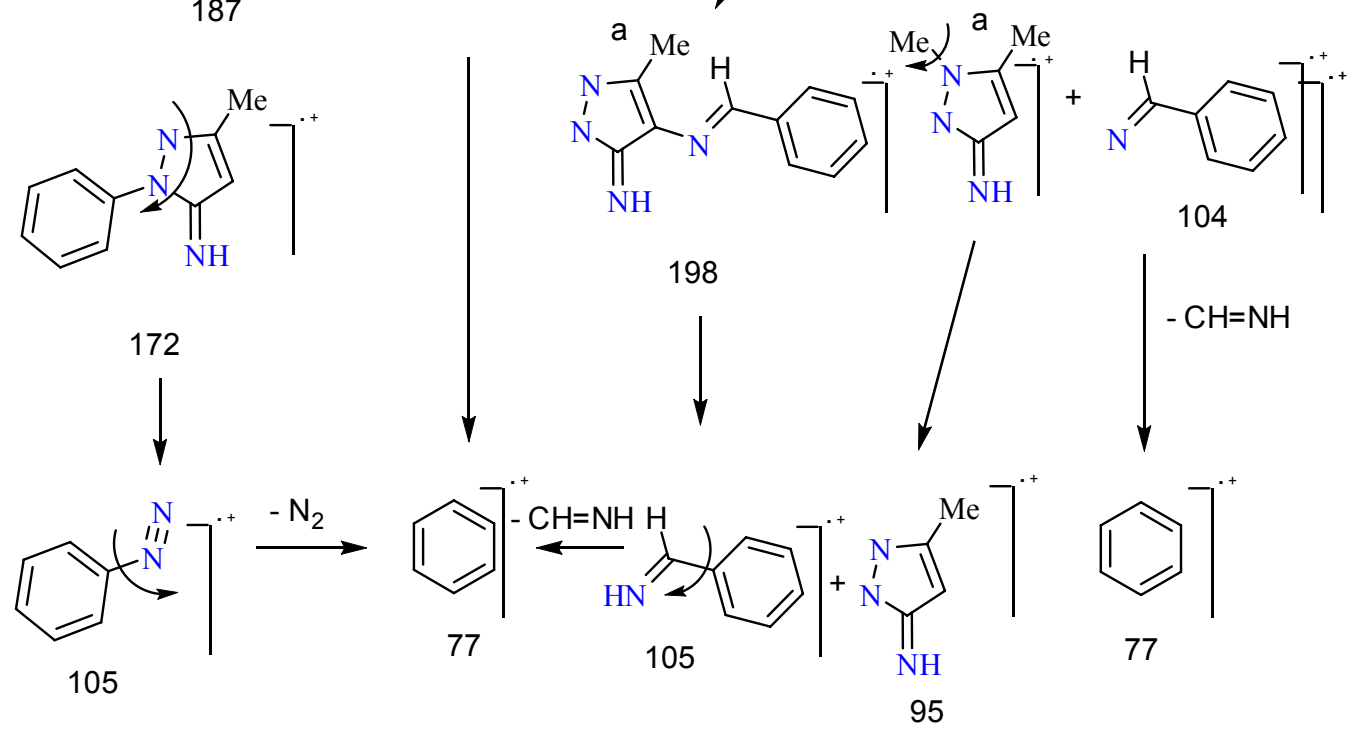

Scheme 1 - Mass fragmentation and molecular ion peaks of AEB Schiff base ligand. 


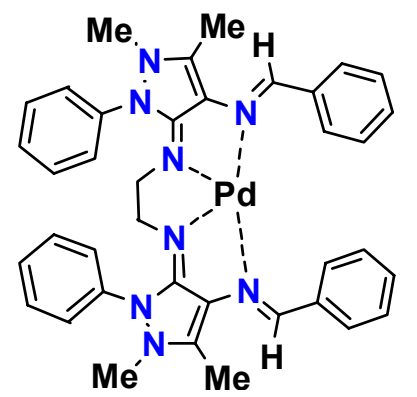

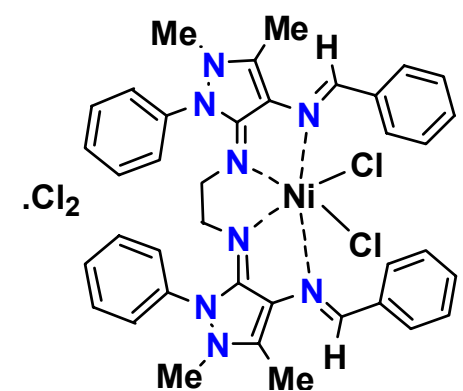

Fig. 2 - Suggested structures of Pd(II) and Ni(II) AEB Schiff base complexes.

5. Analyses

\begin{tabular}{|c|c|}
\hline Analyses & Name of equipment \\
\hline Microanalytical analysis & Perkin Elmer CHN 2400 \\
\hline Molar conductance & $\begin{array}{l}\text { Jenway } 4010 \text { conductivity } \\
\text { meter }\end{array}$ \\
\hline Electronic spectra & UV2-Unicam UV/Vis \\
\hline UV-Vis. & Spectrophotometer \\
\hline Infrared spectra & $\begin{array}{l}\text { Bruker FT-IR } \\
\text { Spectrophotometer }\end{array}$ \\
\hline Thermal analysis & $\begin{array}{l}\text { Shimadzu thermogravimetric } \\
\text { analyzer }\end{array}$ \\
\hline${ }^{1} \mathrm{H},{ }^{13} \mathrm{C}-\mathrm{NMR}$ spectra & $\begin{array}{l}\text { Bruker } 600 \mathrm{MHz} \\
\text { spectrometer }\end{array}$ \\
\hline X-ray diffraction (XRD) & $\begin{array}{l}\text { X Pert Philips X-ray } \\
\text { diffractometer }\end{array}$ \\
\hline $\begin{array}{l}\text { Transmission electron } \\
\text { microscopy }\end{array}$ & JEOL 100s microscopy \\
\hline Magnetic susceptibility & Gouy magnetic balance \\
\hline Mass spectra & $\begin{array}{l}\text { AEI MS } 30 \text { Mass } \\
\text { Spectrometer }\end{array}$ \\
\hline
\end{tabular}

6. Decolorization efficiency

The decolorization studies of methylene blue (MB) dye were performed dependent on the batch adsorption method. The adsorption experiments were carried out at the range of $\mathrm{pH}$ 5-10 using standard solution from $\mathrm{HCl}$ and $\mathrm{NaOH}$, the dosages of oxides (PdO and $\mathrm{NiO}$ ) were from $50 \mathrm{mg}$ to $300 \mathrm{mg}$ and the contact time at 20,40,60,80, 100 and 120 minutes. Adsorption experiments were carried out with a mechanical stirring and the absorbance measurements were performed using spectrophotometer at the maximum wavelength of 662 $\mathrm{nm}$. The decolorization rate of the MB dye was determined as expressed in Eq. (1):

Dye decolorization, $\%=\left(\mathrm{A}_{0}-\mathrm{A}_{\mathrm{t}}\right) / \mathrm{A}_{0} \mathrm{X} 100 \quad$ Eq. (1)

where $A_{t}$ is the absorbance at requested time and $A_{0}$ is the initial absorbance of each solution.

\section{RESULTS AND DISCUSSION}

\section{Characterization of Pd(II) and Ni(II) Schiff base precursors complexes}

\subsection{Preface}

The preparation of the palladium(II) and nickel(II) Schiff base complexes can be designed by the general equation as follows:

$$
\mathrm{MCl}_{2}+\mathrm{AEB} \rightarrow \mathrm{M}(\mathrm{AEB})(\mathrm{Cl})_{2}\left(\mathrm{M}=\mathrm{Pd}^{2+} \text { or } \mathrm{Ni}^{2+}\right)
$$

The AEB Schiff base complexes have a solid brown to greenish brown colored powder. All these complexes are soluble in DMSO and DMF with gently heating, but insoluble in most organic solvents e.g. alcohols, cyclohexan, chloroform, $\mathrm{CCl}_{4}$, benzene and acetone. The elemental analysis results (see section 2-3) deduced that the stoichiometry is 1:1 (metal ions: Schiff base ligand) with formula $\mathrm{M}(\mathrm{AEB})(\mathrm{Cl})_{2}$. The molar conductivity data $\left(94 \Omega^{-1} \mathrm{~cm}^{2} \mathrm{~mol}^{-1}\right)$ of the palladium(II) complex is in the range of expected for $1: 1$ electrolyte, ${ }^{27}$ but the nickel(II) complex is conduct as a non- electrolyte behavior. ${ }^{27}$ Thus, the speculated formula of both palladium and nickel complexes can be designed as $[\mathrm{Pd}(\mathrm{AEB})] \mathrm{Cl}_{2}$ and $\left[\mathrm{Ni}(\mathrm{AEB})(\mathrm{Cl})_{2}\right]$, respectively.

\subsection{FTIR study}

The distinguish infrared spectral data of the AEB Schiff base ligand and its palladium and nickel(II) complexes are given in Table 1. Figure (3) referred to the FTIR spectra of the free AEB ligand and the prepared complexes. In case of the free AEB Schiff base ligand, the FTIR bands presence at 1649 and $1561 \mathrm{~cm}^{-1}$ are due to the $\delta\left(\mathrm{NH}_{2}\right)$ and $v(\mathrm{C}=\mathrm{N})$ stretching vibrations of amino and azomethine groups, respectively. These values are shifted to lower frequencies after complexation. ${ }^{28}$ These vibration bands $\delta\left(\mathrm{NH}_{2}\right)$ and $v(\mathrm{C}=\mathrm{N})$ in the region of $1605-1596 \mathrm{~cm}^{-1}$ and 1542 $1533 \mathrm{~cm}^{-1}$ have been changed in comparison with the free ligand after copmlexation that assigned to the coordinated of nitrogen atoms of both amino and azomethine groups with metal ions. The new weak-to-medium bands in the region of 500$400 \mathrm{~cm}^{-1}$ were observed in the spectra of metal complexes, which didn't present in the spectra of free ligand due to the stretching vibration of $v(\mathrm{M}-\mathrm{N}){ }^{28}$ 


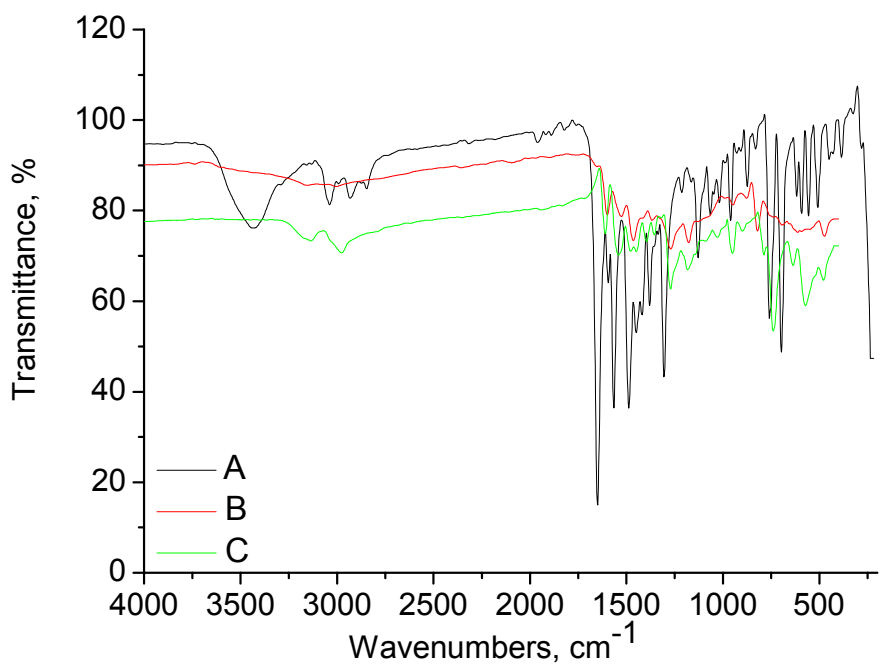

Fig. 3 - Infrared spectra of A: AEB Schiff base ligand, B: nickel(II) and C: palladium(II) complexes.

Table 1

FT-IR assignments of free AEB Schiff base ligand and its Ni(II) and Pd(II) complexes

\begin{tabular}{c|c|c|c|c}
\hline \multirow{2}{*}{ Compounds } & \multicolumn{4}{|c}{ Assignments $\left(\mathbf{c m}^{\mathbf{- 1}} \mathbf{~}\right.$} \\
\cline { 2 - 5 } & $\mathbf{v ( N H ) ;} \mathbf{N H}_{\mathbf{2}}$ & $\delta\left(\mathbf{N H}_{\mathbf{2}}\right)$ & $\mathbf{v ( C = N )}$ & $\mathbf{v}(\mathbf{M}-\mathbf{N})$ \\
\hline AEB ligand & 3322 & 1649 & 1561 & - \\
Pd(II) complex & 3154 & 1596 & 1533 & 473 \\
Ni(II) complex & 3140 & 1506 & 1542 & 472 \\
\hline
\end{tabular}

\subsection{Electronic and magnetic study}

The electronic spectrum of synthesized AEB Schiff base ligand shows two band maxima at 26595 and $34130 \mathrm{~cm}^{-1}$ due to $\mathrm{n} \rightarrow \pi^{*}$ and $\pi \rightarrow \pi^{*}$ transitions, respectively. ${ }^{29}$ In case of palladium and nickel(II) complexes, both of $n \rightarrow \pi^{*}$ and $\pi \rightarrow \pi^{*}$ bands are found to be blue shifted compared to that of AEB ligand. The electronic spectrum of a diamagnetic palladium(II) complex has three absorption bands at $26316 \mathrm{~cm}^{-1}, 31446 \mathrm{~cm}^{-1}$ and $18868 \mathrm{~cm}^{-1}$ which assigned to ${ }^{1} \mathrm{~A}_{1 \mathrm{~g}} \rightarrow{ }^{1} \mathrm{~A}_{2 \mathrm{~g}}$, ${ }^{1} \mathrm{~A}_{1 \mathrm{~g}} \rightarrow{ }^{1} \mathrm{~B}_{1 \mathrm{~g}}$ and $\mathrm{L} \rightarrow \mathrm{M}_{\mathrm{CT}}$, respectively, ${ }^{30}$ which is characteristic of square planar electronic configuration. The magnetic moment of $\mathrm{Ni}$ (II) complex is 5.37 B.M and the spectrum of this complex displayed three bands at $25252 \mathrm{~cm}^{-1}$, $14706 \mathrm{~cm}^{-1}$ and $13477 \mathrm{~cm}^{-1}$ which may have assigned to ${ }^{3} \mathrm{~A}_{2 \mathrm{~g}}(\mathrm{~F}) \rightarrow{ }^{3} \mathrm{~T}_{1 \mathrm{~g}}(\mathrm{~F}),{ }^{3} \mathrm{~T}_{1 \mathrm{~g}}(\mathrm{P}) \rightarrow{ }^{3} \mathrm{~A}_{2 \mathrm{~g}}$ and $\mathrm{L} \rightarrow \mathrm{M}_{\mathrm{CT}}$, respectively, therefore an octahedral configuration suggested. ${ }^{29}$

\section{4. ${ }^{1} \mathrm{H},{ }^{13} \mathrm{C}-\mathrm{NMR}$ spectral study}

From the ${ }^{1} \mathrm{H},{ }^{13} \mathrm{C}-\mathrm{NMR}$ spectral data, the chelating of the palladium metal ions with the AEB Schiff base ligand let to change in the electronic environment of the total complex which resulted in a downfield shift in each of proton and carbon NMR, where, the two methyl groups in ${ }^{1} \mathrm{HNMR}$ shifted from $\delta=2.18$ and 2.69 to 2.13 and $2.76 \mathrm{ppm}$ while the protons of $2 \mathrm{NCH}_{3}$ shifted from 3.11 to $3.42 \mathrm{ppm}$ where the electronic density over the nitrogen atom decreases due to the complexation. In case of ${ }^{13} \mathrm{CNMR}$ spectra, it is showed an upfield shift from 12.59 to $9.87 \mathrm{ppm}$ regarding the two methyl groups, while the $\mathrm{CH}_{2}$ showed a downfield shift from 34.83 to $40.12 \mathrm{ppm}$.

\subsection{Thermal analysis study}

The thermogravimetric and differential thermogravimetric curves of palladium complex, $[\mathrm{Pd}(\mathrm{AEB})] \mathrm{Cl}_{2}$ are displayed in Fig. 4a. These curves referred to the decomposition of palladium(II) complex in only one stage within the temperature range of $25^{\circ} \mathrm{C}-800^{\circ} \mathrm{C}$ at $\mathrm{DTG}_{\text {max }}$ peak equal $275^{\circ} \mathrm{C}$, and a mass loss of $84 \%$, which can be attributed to the decomposition of AEB ligand and the chlorine molecules. The thermal degradation process is completed at $300^{\circ} \mathrm{C}$ and the $\mathrm{PdO}$ is a residual solid product. The nickel(II) complex, $\left[\mathrm{Ni}(\mathrm{AEB})(\mathrm{Cl})_{2}\right.$ ] decomposes in two steps (Fig. 4b) with a weight loss of $90 \%$ at a temperature range of $25-800^{\circ} \mathrm{C}$ due to the removal of the AEB ligand and chlorine molecules. The DTG $_{\max }$ peak due to these two stages are observed at 240 and $450^{\circ} \mathrm{C}$. The residue of $10 \%$ at $800{ }^{\circ} \mathrm{C}$ is nickel(II) oxide (calcd. 10.14\%). 


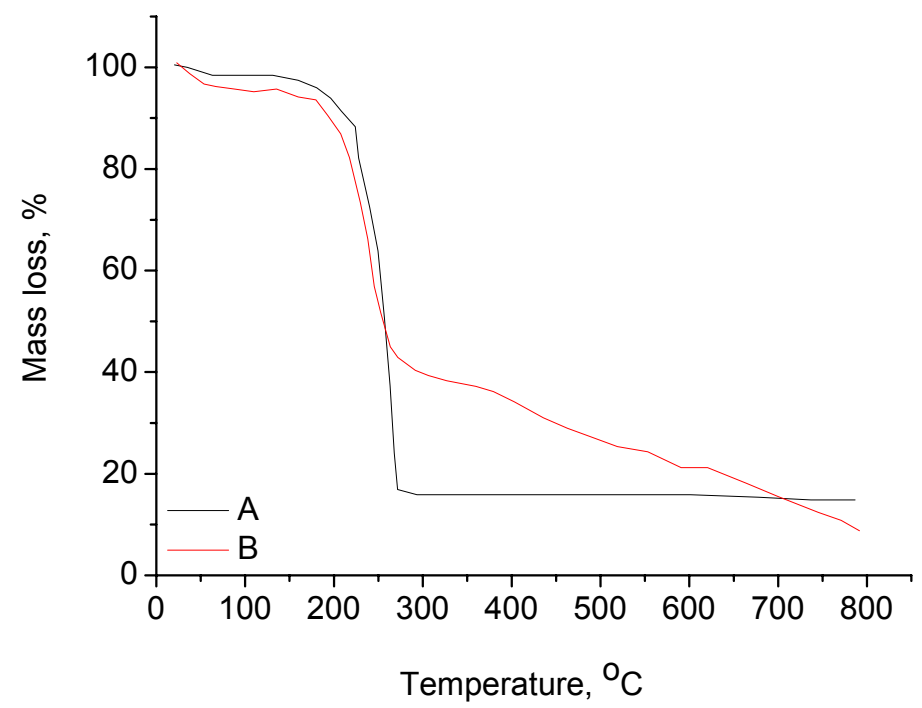

Fig. 4 - TGA thermograms of A: Pd(II) and B: Ni(II) Schiff base complexes.

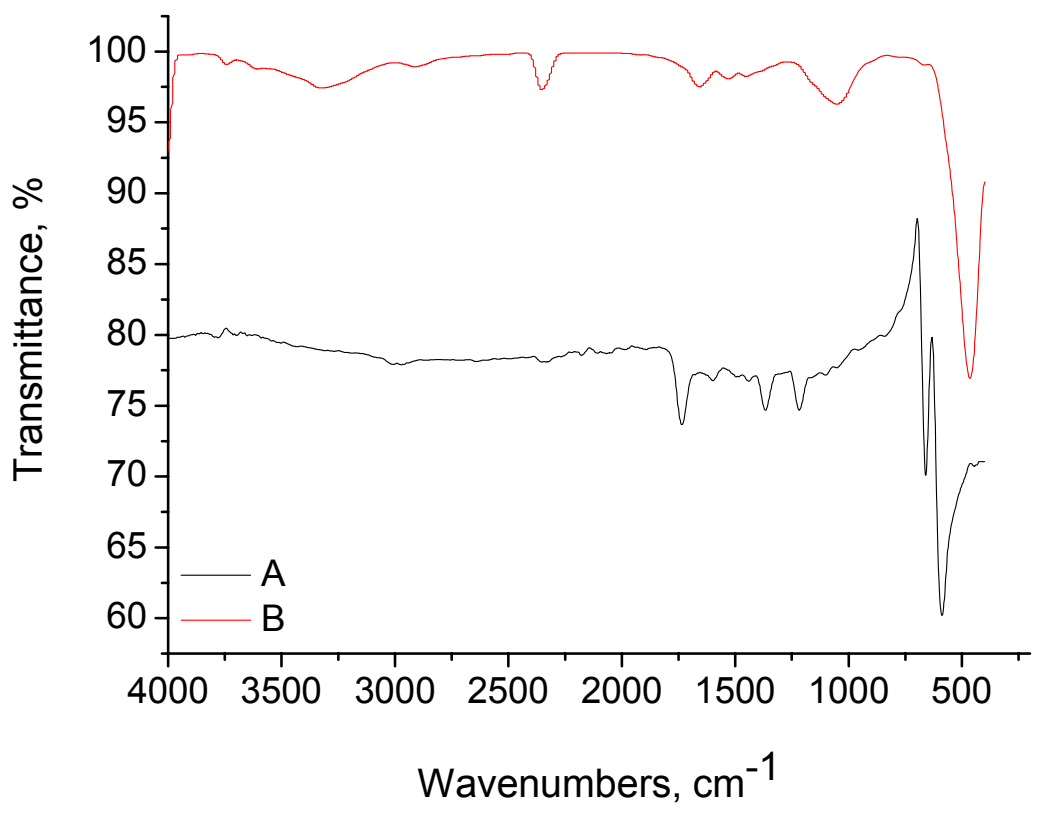

Fig. 5 - FT-IR spectra of (A): PdO and (B): NiO NPs oxide calcinated at $800^{\circ} \mathrm{C}$.

\section{Characterizations of synthesized PdO and NiO NPs}

\subsection{FTIR study}

Figure 5A display the FTIR spectrum of the synthesized palladium(II) oxide NPs after calcinations of palladium(II) Schiff base complex, $[\mathrm{Pd}(\mathrm{AEB})] \mathrm{Cl}_{2}$ at $800{ }^{\circ} \mathrm{C}$. The weak-to-weak bands exhibited at 1601 and $1213 \mathrm{~cm}^{-1}$ are assigned to stretching and deformation of hydrated water adsorbed on the surface of metal oxide, while the two new bands at 660 and $595 \mathrm{~cm}^{-1}$ are assigned to $\mathrm{Pd}-\mathrm{O}$ stretching vibrations. ${ }^{31}$ The other band occurs at $1370 \mathrm{~cm}^{-1}$ is assigned to the stretching vibration motion of peroxo groups. ${ }^{32}$ After calcinations of nickel(II) Schiff base complex at $800{ }^{\circ} \mathrm{C}$ for $3 \mathrm{~h}$, the green powder from nickel oxide (NiO) was formed. The FTIR spectrum (Fig. 5B) has included three stretching vibration bands at 3319,1658 and $1062 \mathrm{~cm}^{-1}$ due to the presence of hydrated water molecules on the surface of nickel oxide, while the fourth vibration band located at $465 \mathrm{~cm}^{-1}$ is assigned to $\mathrm{Ni}-\mathrm{O}$ stretching vibration of $\mathrm{NiO}$ oxide structure. ${ }^{33}$

\subsection{XRD and TEM studies}

$\mathrm{X}$-ray powder diffraction of the prepared $\mathrm{PdO}$ and its crystal planes are shown in Fig. 6a. This 
data agreement with standard PdO (JCPDS card No. 03-065-5261) and the average size of the PdO NPs $(28 \mathrm{~nm})$ was calculated using the DebyeScherrer equation. ${ }^{34,35}$ TEM image of the PdO (Fig. 6b) is refer to the presence of PdO NPs in spherical shapes with agglomeration. The particle size calculated by TEM micrograph $(28-40 \mathrm{~nm})$ is agreement with XRD. The XRD diffraction pattern of the NiO NPs is presence in Fig. 7a, it confirms the formation of cubic NiO (JCPDS card No. 780643). ${ }^{36}$ TEM micrograph of $\mathrm{NiO}$ oxide is clearly refer that the $\mathrm{NiO}$ has an average size between $13 \mathrm{~nm}$ (Fig. 7b).
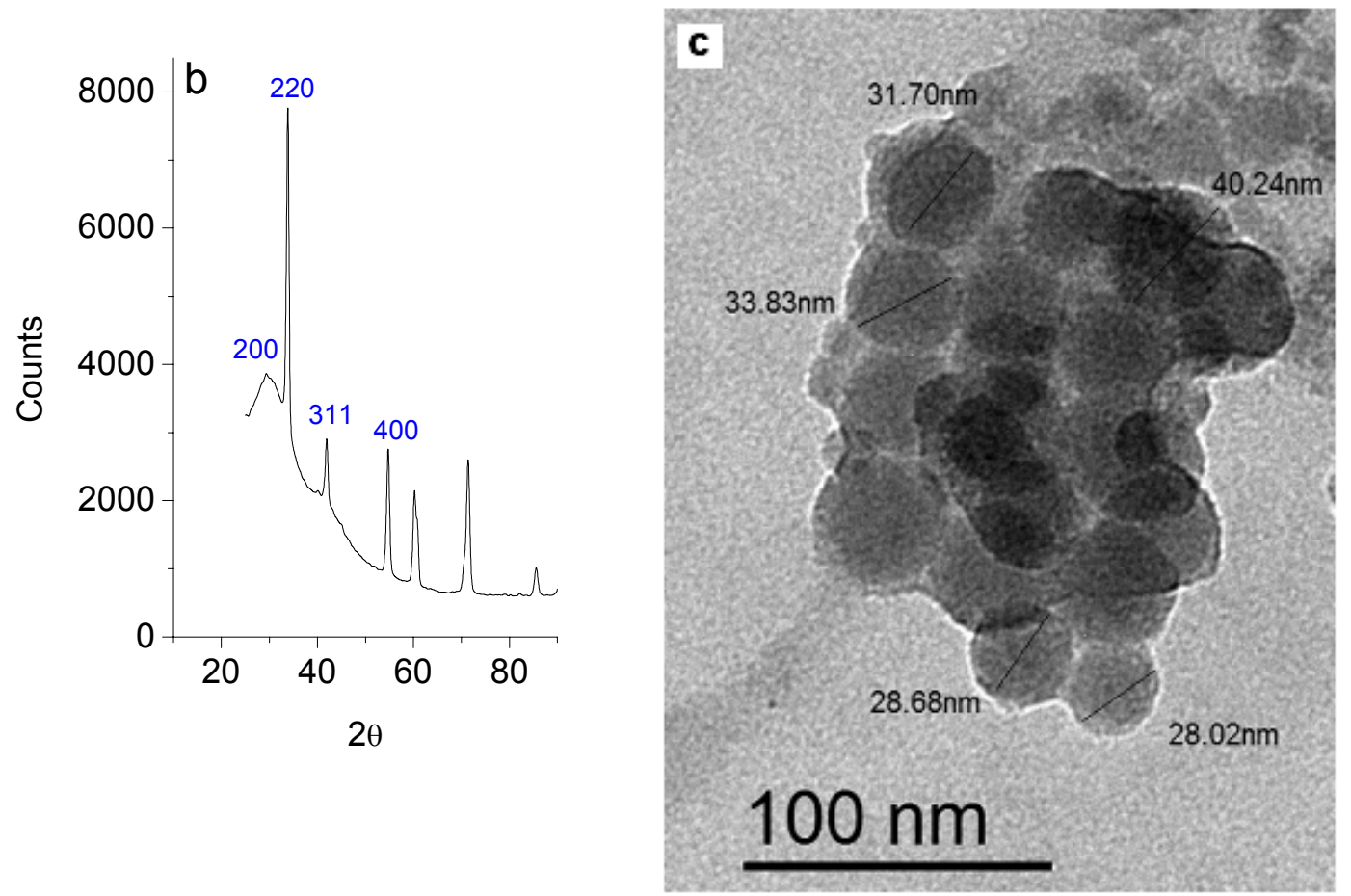

Fig. 6 - (a): XRD spectrum and (b): TEM micrograph of the PdO NPs oxide calcinated at $800{ }^{\circ} \mathrm{C}$.
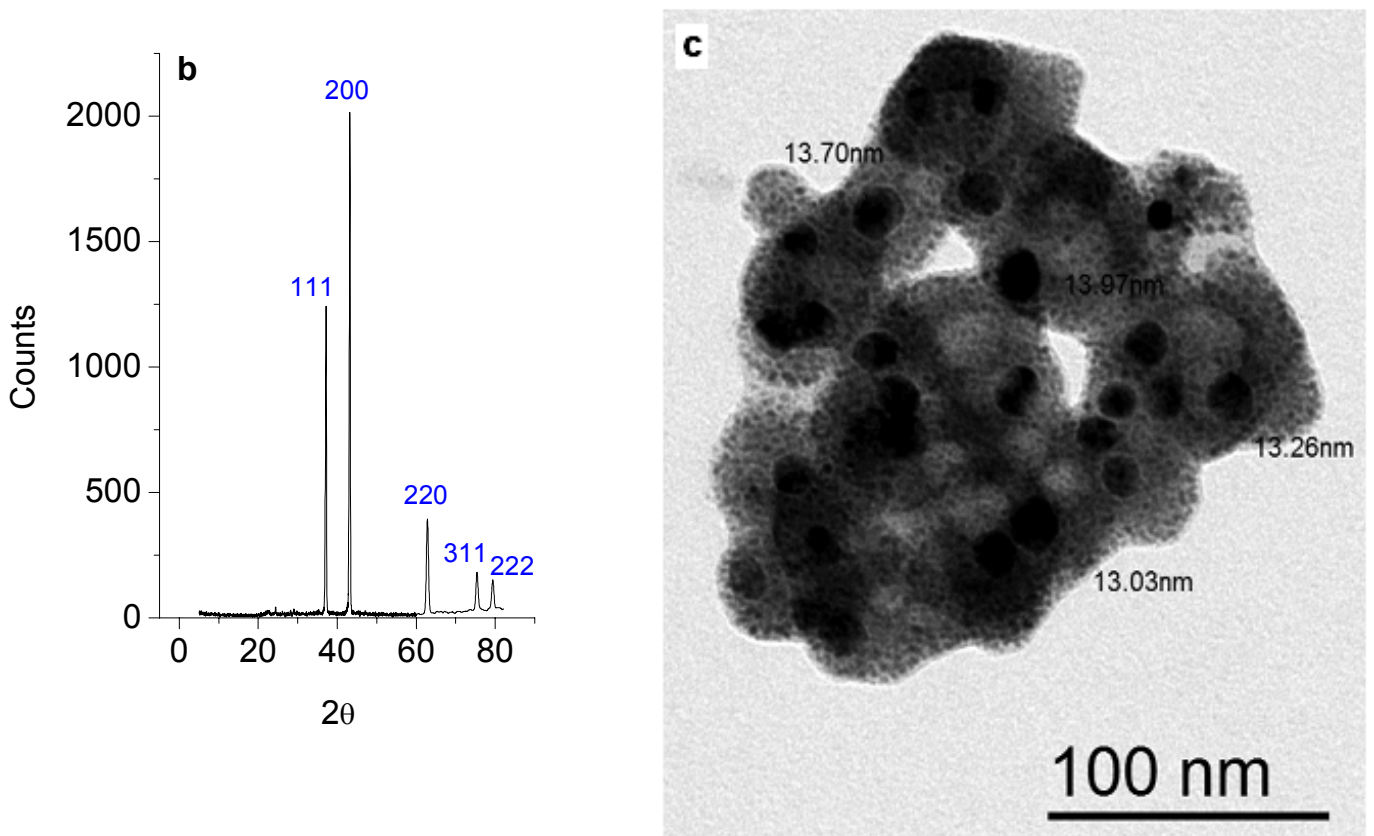

Fig. 7 - (a): XRD spectrum and (b): TEM micrograph of the NiO NPs oxide calcinated at $800{ }^{\circ} \mathrm{C}$. 


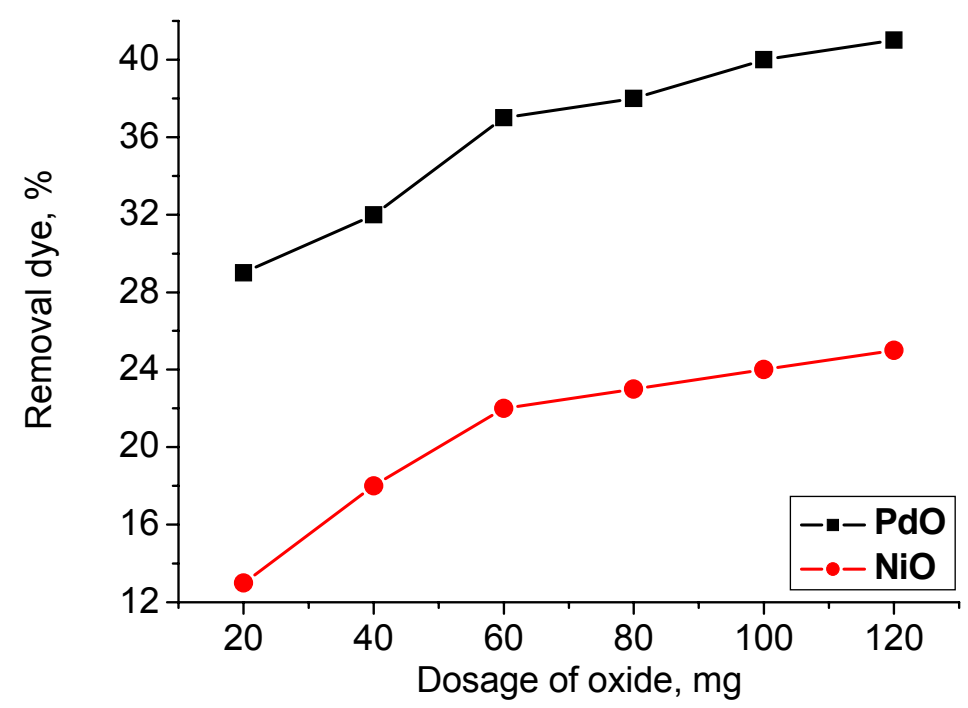

Fig. 8 - Influence of dosage from $\mathrm{PdO}$ and $\mathrm{NiO}$ oxide NPs on the removal of MB dye at variable mass (mg).

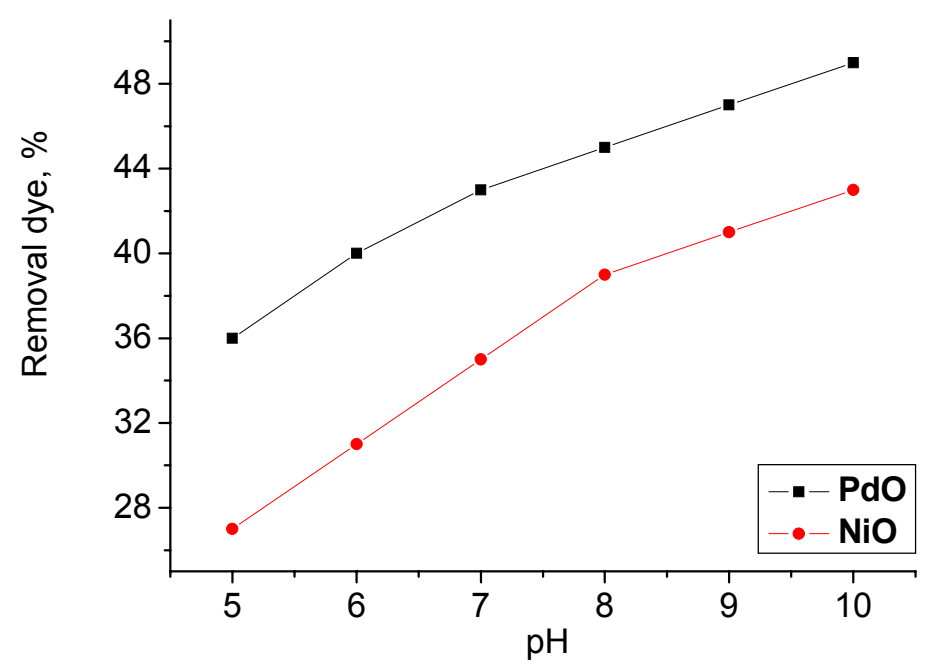

Fig. 9 - Influence of $\mathrm{pH}$ medium on the removal of MB dye at variable values using PdO and NiO oxides NPs.

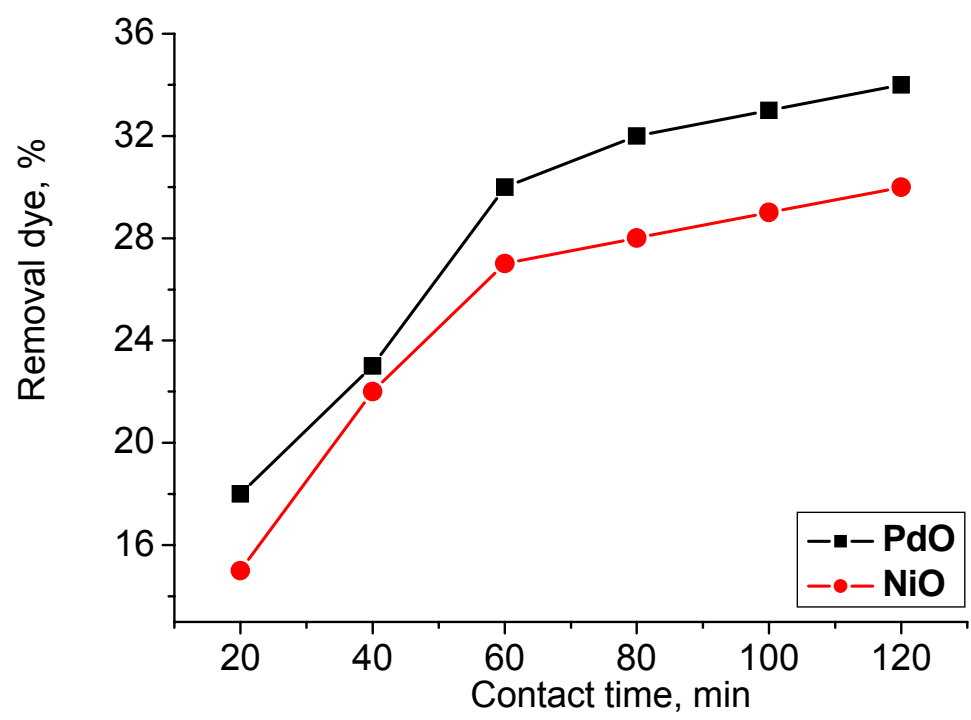

Fig. 10 - Influence of contact time on the removal of MB dye at variable time (min) for the PdO and NiO oxides NPs. 


\section{Decolorization efficiency studies}

Figure 8 refers to the effect of $\mathrm{PdO}$ and $\mathrm{NiO}$ oxide dosages to acts as adsorbent for methylene blue (MB) dye. The resulted data showed that an increase in the dose of adsorbents could increase adsorption capacity. As the adsorption dose increased, the surface area was available for adsorption due to the increase in the active site on the surface of adsorbent and thus facilitate penetration of oxide NPs to make adsorption. The optimal performance dosage from synthetic oxides ( $\mathrm{PdO} \& \mathrm{NiO})$ to adsorb $\mathrm{MB}$ dye at a fixed of 60 $\mathrm{mg} / \mathrm{L}$. The adsorption process referred that the $\mathrm{pH}$ medium of the MB solutions has an expressive effect on the adsorption capacity of the adsorbent (metal oxides). The adsorption experiments in basic medium $(\mathrm{pH}=10)$ is the highest efficiency, that when the $\mathrm{pH}$ of the solution is in acidic media $(\mathrm{pH}=5)$, the efficient of the adsorbed dye on the surface of adsorbent is decreased. ${ }^{37}$ This phenomenon appears clearly in the case of PdO rather than $\mathrm{NiO}$ (Fig. 9). The effect of contact time on the removal dye color also increased with increasing the contact time as shown in Fig. 10. The optimal contact time is at $60 \mathrm{~min}$ then after that the decolorization efficient was steady stable. In this optimum condition, the adsorption efficiency of the removal dye was $34 \%$ and $30 \%$ in case of $\mathrm{PdO}$ and $\mathrm{NiO}$ adsorbents, respectively, so that extra time doesn't affect in the removal of coloring dye. The present study showed that PdO and $\mathrm{NiO}$ nanoparticles were an effective adsorbents for the removal of $\mathrm{MB}$ from aqueous solution. The outcome data deduced that the adsorption efficiency of MB on synthetic adsorbent $(\mathrm{PdO} \& \mathrm{NiO})$ increased with alkaline $\mathrm{pH}$, increased with increasing dose of adsorbents and contact time. ${ }^{38}$

\section{CONCLUSIONS}

In this study $\mathrm{PdO}$ and $\mathrm{NiO}$ nanoparticles were prepared using 4-aminoantipyrine, benzaldehyde and ethylenediamine as starting material by sol gel method followed by calcinations at $800^{\circ} \mathrm{C}$. The solid product was characterized by X-ray diffraction (XRD), scanning electron microscopy (SEM), transmission electron microscopy (TEM) and Fourier transform infrared (FTIR) techniques. The particle size of the NPs estimated by XRD was in good agreement with the particle size obtained by TEM analysis (13-28 nm). It was also found that the prepared $\mathrm{PdO} \& \mathrm{NiO}$ show good activity for catalytic degradation of dye organic pollutants such as methylene blue (MB) with removal efficiency of $34 \%$ and $30 \%$ in case of $\mathrm{PdO}$ and $\mathrm{NiO}$ adsorbents, respectively.

Acknowledgements. This research was funded by the Deanship of Scientific Research at "Princess Nourah bint Abdulrahman University", through the Research Funding Program (Grant No. \# 39/260).

\section{REFERENCES}

1. M. A. G. U. de Selen Souza, L. C. Antonio Peruzzo and A. U. de Souza, Appl. Math. Model, 2008, 32, 1711-1718.

2. M.-H. Baek, C. O. Ijagbemi, S.-J. O and D.-S. Kim, J. Hazard. Mater., 2010, 176, 820-828.

3. R. Ahmad and R. Kumar, J. Environ. Manag., 2010, 91, 1032-1038.

4. B. D. Santos, F. J. Cervantes and J. B. Vanlier, Bioresour. Technol., 2007, 98, 2369-2385.

5. S. Senthilkumaar, P. R. Varadarajan, K. Porkodi and C. V. Subbhuraam, J. Colloid Interface Sci., 2005, 284, 78-82.

6. K. Shakir, A. F. Elkafrawy, H. F. Ghoneimy, S. G. E. Beheir and M. Refaat, Water Research, 2010, 44, 14491461.

7. P. K. Malik and S. K. Saha, Separ. Sci. Tech., 2003, 31, 241-250.

8. G. Ciardelli, L. Corsi and M. Marucci, Resour. Conserv. Recy., 2000, 31, 189-197.

9. I. DeoMall, V. C. Srivastava, N. K. Agarwal and I. M. Mishra, Chemosphere, 2005, 61, 492-501.

10. A. Spagni, S. Grilli, S. Casu and D. Mattioli, Int. Biodeter. Biodegr., 2010, 64, 676-681.

11. A. Gürses, Ç. DoXar, M. Yalçin, M. Açikyildiz, R. Bayrak and S. Karaca, J. Hazard. Mater., 2006, 131, 217-228.

12. E. K. Shirazi, J. W. Metzger, K. Fischer and A. H. Hassani, Chemosphere, 2019, 234, 618-629.

13. L. Y. Li, X. Gong and O. Abida, Waste Management, 2019, 87, 375-386.

14. D. S. W. Palagama, A. M. Devasurendra, D. BaliuRodriguez, J. R. Kirchhoff and D. Isailovic, Sci. Total Environ., 2019, 666, 1292-1300.

15. S. Gamoudi and E. Srasra, J. Mol. Struct., 2019, 1193, $522-531$.

16. S. Razani and A. D. Tehrani, Int. J. Biol. Macromol., 2019, 133, 892-901.

17. V. Leso and I. Iavicoli, Int. J. Mol. Sci., 2018, 19, 503.

18. A. Jafari, S. P. Jahromi, K. Boustani, B. T. Goh and N. M. Huang, J. Mag. \& Mag. Mater., 2019, 469, 383-390.

19. J. Du, S. Cao, A. I. Munoz and S. Mischler, Wear, 2019, 1496, 426-427.

20. R. Sankannavar, K. C. Sandeep, S. Kamath, A. K. Suresh and A. Sarkar, Electrochim. Acta, 2019, 318, 809-819.

21. K. Kruanak and C. Jarusutthirak, J. Environ. Chem. Eng., 2019, 7, 102825 .

22. Y. Zhang, L. Du, X. Liu and Y. Ding, Appl. Surf. Sci., 2019, 481, 138-143.

23. I. Iavicoli, B. Bocca, S. Caroli, S. Caimi, A. Alimonti, G. Carelli and L. Fontana, J. Occup. Environ. Med., 2008, 50, 1158-1166.

24. R. Narayanan and M. A. El-Sayed, J. Phys. Chem. B, 2005, 109, 12663-12676. 
25. K. S. Siddiqi and A. Husen, Nanoscale Res. Lett., 2016, 11, 482-494.

26. K. S. A. Abou Melha, G. A. A. Al-Hazmi and M. S. Refat, Russ. J. Gen. Chem., 2017, 87, 3043-3051.

27. M. S. Refat, J. Mol. Struct., 2007, 842, 24-37.

28. K. Nakamoto "Infrared and Raman Spectra of Inorganic and Coordination Compounds", Wiely, New York, 1978.

29. A. B. P. Lever, "Inorganic Electronic Spectroscopy", $2^{\text {nd }}$ Edition, Elsevier, Amsterdam, 1984.

30. S. Chandra, S. Verma and P. Meera, J. Indian Chem. Soc., 2008, 85, 896-900.

31. C.N.R. Rao, "Chemical applications of infrared spectroscopy", Academic Press, New York and London, 1963.
32. Y. Wang and N. Herron, J. Phys. Chem., 1991, 95, 525-532.

33. T. Ahmad, K. V. Ramanujachary, S. E. Lofland and A. K. Ganguli, Solid State Sci., 2006, 8, 425-430.

34. A.D. Khalaji, J. Clust. Sci., 2013, 24, 189-195.

35. B.D. Cullity, "Elements of X-ray Diffraction", AddisonWesley, Reading, MA, 1972, p. 102.

36. S. M. Meybodi, S. A. Hosseini, M. Rezaee, S. K. Sadrnezhaad and D. Mohammadyani, Ultrasonic Sonochem., 2012, 19, 841-845.

37. M. Stoyanova and S. Christoskova, Cent. Eur. J. Chem., 2011, 9, 1007-1000.

38. H. Y. Zhu, Y. Q. Fu, R. Jiang, L. Xiao, G. M. Zeng and S. L. Zhao, Y. Wang, Chem. Eng. J., 2011, 173, 494-502. 